\title{
Reptiles traded in markets for medicinal purposes in contemporary Morocco
}

\author{
Vincent Nijman ${ }^{1,2,3}$, Daniel Bergin ${ }^{1,2}$ \\ ${ }^{1}$ Oxford Wildlife Trade Research Group, Oxford Brookes University, OXO 1BP, Oxford, UK \\ ${ }^{2}$ Little Fireface Project, Rumah Hijau, RT 01 / RW 04 Jalan Merpati, Cipaganti, Cisuru pan, Garut, West Java, \\ Indonesia \\ ${ }^{3}$ E-mail:vnijman@brookes.ac.uk
}

Key words: Bern Convention, CITES, ethnozoology, traditional medicine, wildlife trade

\begin{abstract}
Reptiles are traded globally for medicinal purposes. Historic qualitative accounts of reptiles used as medicine in Morocco are numerous, but contemporary quantitative data are rare. In 20132014, we surveyed 49 wildlife markets in 20 towns throughout Morocco, plus the Spanish exclaves of Ceuta and Melilla. We recorded 1,586 specimens of at least nine species for sale in 14 of the Moroccan markets with a combined value of about US $\$ 100,000$. The most prominent markets were those in Marrakesh, Meknes, Casablanca, and Fez, with the former two cites trading equal quantities of dried and live specimens and the latter two trading mainly dried specimens. Common species were the Mediterranean chameleon (Chamaeleo chamaeleon) with 720 specimens (506 dried, 214 alive) and the Bell's Dabb lizard (Uromastyx acanthinura) with 428 specimens (247 dried, 181 alive), both traded in 10 markets, and spur-thighed tortoise (Testudo graeca; 57 carapaces), for sale in eight cities. Over 200 African rock python (Python sebae) skins were identified and may have been illicitly imported from other parts of Africa. The turnover of Mediterranean chameleon and Bell's Dabb lizard specimens after four weeks as measured by repeat surveys was $66 \%$ for both species, resulting in an estimated annual turnover of 1,520 chameleons (range 921-2,303) and 775 lizards (range 364-1,174). Despite legal protection and regulations locally within Morocco and internationally through CITES, reptiles are commonly and openly traded for medicinal purposes throughout Morocco. However, traders are not forthcoming in conveying the legal status of these species and restrictions on trade to potential buyers. Increased enforcement of existing wildlife protection legislation is needed to prevent this exploitation from the illegal wildlife trade that could negatively impacts imperiled species.
\end{abstract}

\section{Contents}

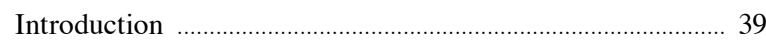

Material and methods ................................................................ 40

Data acquisition .................................................................... 40

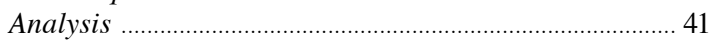

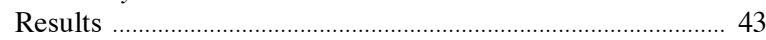

Volume and value of the trade .......................................... 43

Comparing markets ............................................................... 44

Species in trade and their medicinal uses ....................... 45
International trade in pythons and crocodiles

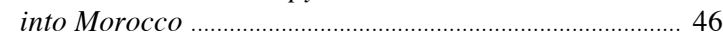

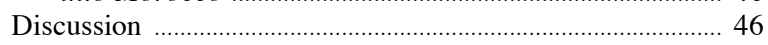

Generalities of the trade and its uses ................................ 46

Legality and regulation of the trade ................................. 48

Acknowledgements .............................................................. 49

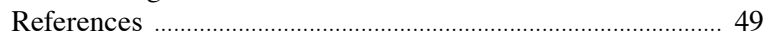

\section{Introduction}

Drugs made from leaves, herbs, roots, bulbs, bark, animals, animal parts, and animal derivatives are widely listed in the pharmacopoeias of folk societies and in traditional medicine (Adeola, 1992; Still, 2003; Mahawar and Jaroli, 2008; Whiting et al., 2013; Segniagbeto et al., 2013). Ingredients derived from wild plants and animals are important in the preparation of traditional remedies and the usefulness of these substances has been long recognized in modern evidence-based medicine. For instance, an analysis in 2010 showed that more than two-thirds of all drugs discovered over the previous 30 years were derived from natural products (Newman and Cragg, 2012). Certain types of medicine can become so popular, sometimes spreading outside the region in which they were initially used, that the extraction of the raw material from the wild becomes an impediment to biodiversity conservation. It has been noted that some of the lesser known and smaller species can be negatively affected by the trade for traditional medicine (Sadovy and Cheung, 2003; Nijman et al., 2012a; Humle and Konate, 2015; Byard, 2016; Rowley et al., 2016). Reptiles (including turtles, tuataras, lizards, snakes, and crocodiles) are widely used in folk and traditional medicine (Zhou and Jiang, 2004; Alves et al., 2008, 2009; Magnino et al., 2009; Segniagbeto et al.,2013), and there are numerous examples in which their use has led to the decline of species (Gong et al., 2009; Nijman et al., 2012a, b; Caillabet, 2013). 
Morocco is an area of particular concern with respect to the species declines, including those from medicinal uses. With 99 species of reptiles, Morocco is one of the Mediterranean countries with the highest diversity of herpetofauna (Cox et al., 2006), in part because of the high levels (around 25\%) of endemism (Pleguezuelos et al., 2010). Endemic reptiles include the Moroccan glass lizard (Ophisaurus koellikeri Günther, 1873), mountain viper (Vipera monticola Saint-Girons, 1954), Moroccan worm lizard (Blanus mettetali Bons, 1963), Tangier worm lizard, (B. tingitanus Busack 1988), and, possibly, Moroccan spiny lizard (Uromastyx nigriventris Rothschild and Hartert, 1912) (see Harris et al., 2007), the latter here treated as part of Bell's Dabb lizard (U. acanthinura Bell, 1825). Many species are vulnerable due to intrinsic factors such as restricted range, low density, and limited dispersal capacity. These threats are followed in importance by habitat loss, accidental mortality, and accidental harvesting (Pleguezuelos et al., 2010). Endemic, or otherwise small-ranged, species are also potentially vulnerable to climate change (Martínez-Freiría et al., 2013). The main causes of habitat loss and habitat degradation are due to land use changes, with an increasing proportion being used for intense agriculture (Cox et al., 2006; van Lavieren and Wich, 2010). According to Pleguezuelos et al. (2010), harvesting for traditional medicine and entertainment is a serious threat to reptiles in Morocco, particularly to snakes.

Compared to many other societies, the use of reptiles in traditional medicine in Morocco has been relatively well documented. However, contemporary quantitative accounts are rare. Jackson (1810) reported on the trade in the Mediterranean chameleon (Chamaeleo chamaeleon Linnaeus, 1758) in the cities that are currently known as Marrakesh and Fez, noting that both the meat and the dried bodies were sold in drug shops. A few decades later, Leared (1876) reported on the medicine used by Moroccans, using data and specimens collected primarily at Marrakesh and Essaouira. The majority of his report concerns medicine derived from plants and reptiles. Like Jackson, he singled out the Mediterranean chameleon as a species of particular importance in trade. Fifty years later, Westermarck (1926) wrote a treaty on the rituals and beliefs of the Moroccans and devoted a significant section to the medicinal uses of and mysticism surrounding animals, including spur-thighed tortoises (Testudo graeca Linnaeus, 1758), chameleons, lizards, and especially snakes. Fogg $(1938,1941)$ reported on the uses of plants, animals, and minerals as used by a single traditional folk doctor in the northernmost part of the country bordering the Mediterranean Sea. He gave accounts of the medicinal uses for Mediterranean chameleons, a lizard (possibly either Atlas dwarf lizard, (Atlantolacerta andreanskyi Werner, 1929), North Africa eyed lizard, (Timon tangitanus Boulenger, 1887) or Tunisian eyed lizard, (Timon pater Lataste, 1880)), and skin and fat of snakes.

More recent accounts of use of reptiles included those by Akhmisse (1985), who focused strongly on the mystical aspects but who singled out the Mediterranean chameleon and the spur-thighed tortoises for medicinal uses, and Meziane (2003), who gave a contemporary account of the use of traditional medicine in the town of D'Oujda and highlighted the use of chameleons and snakes. Although there was no mention of their use in medicine, Znari et al. (2005) found 692 spur-thighed tortoises in the markets at Marrakesh in 2001, a high proportion of which were small individuals. Highfield and Bayley (2007) gave a brief overview of the folklore, myths, and exploitation of reptiles in Morocco (and Tunisia), but added few new quantitative data. Finally, and most recently, Martin and PerryMartin (2012) reported on the wildlife trade. They recorded an unknown number of live Mediterranean chameleons and other lizards for sale in Fez as well as dried Mediterranean chameleons and stuffed iguanas (Iguana spp.) in Marrakesh, but provided few additional details.

Here we focus on the trade of reptiles to be used for medicinal purposes as observed in the open markets throughout Morocco. We conducted repeat surveys of a large number of markets, quantified species compositions and volumes in trade, and documented purported medicinal properties and uses. Some of the species we documented in trade are considered globally or regionally threatened with extinction (Pleguezuelos et al., 2010) and we aim to better our understanding of the threat that traditional medicinal trade in Morocco poses to the species and to report ways in which the trade of imperiled reptiles are regulated.

\section{Material and methods}

\section{Data acquisition}

We surveyed the wildlife markets in 20 towns throughout Morocco in April to June 2013, April to May 2014, and December 2014, as well as the Spanish exclaves of Ceuta and Melilla in northern Morocco in April 2014 


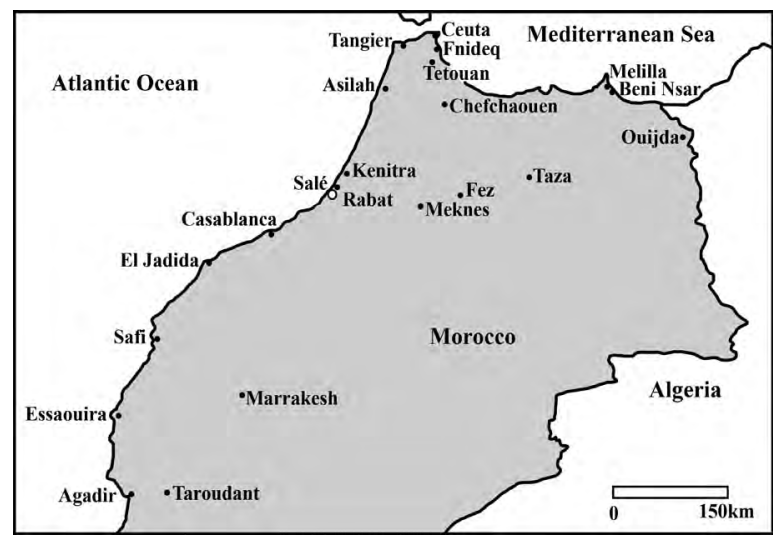

Fig. 1. Map of Morocco showing the towns that were surveyed between April 2013 and December 2014 for the presence of reptiles used for medicinal purposes.

(Fig. 1). We selected the towns to include all of the larger ones (including the capital Rabat), important trade hubs (including ferry ports such as Tangiers), and two border towns. We visited 13 markets only once, but surveyed others up to six times over all three survey periods. The total survey effort was 49 visits. We identified and counted reptiles sold for medicinal purposes, and we gathered data on usages and prices through informal conversations with vendors and medicine dispensers. In towns that we surveyed only once, we selected the vendors with whom we held conversations (in French or, when initiated by the vendor in English) to represent as much as possible the variety of trade that was on offer. In towns that were re-surveyed, we ensured that individual traders were not included twice.

While individual vendors were not necessarily able or willing to provide information on all species on display, unlike the report of Fogg (1941), we communicated with a large number of vendors and herbalists who allowed us to build up a narrative of the trade and the uses of reptiles. We made most species identifications in the market itself. However, over the course of the study, we were able to photograph a large number of items, thus allowing us to verify our market identifications. We visited the markets of Marrakesh, Casablanca, Meknes, and Fez multiple times, providing the greatest amount of data on the use of reptiles for medicinal purposes. We use data from these four towns to provide a more detailed account, including more detailed analysis, of this trade.

Data on the import of African rock python (Python sebae Gmelin, 1788) and Nile crocodile (Crocodylus niloticus Laurenti, 1768), two species that are not, or are no longer, native to Morocco, were obtained from the Convention on International Trade in Endangered Species of Wild Fauna and Flora (CITES) trade database (www.cites.trade.org). These two species are listed on the CITES appendices and all import and export between parties needs to be reported to the CITES Secretariat annually. Morocco is a party to CITES, as are all countries in the ranges of the African rock python and Nile crocodile. We retrieved both data on the import as reported by Morocco and on the export to Morocco as reported by other countries.

\section{Analysis}

Several species that are sold for medicinal purposes are also traded for other uses (e.g., to be used as pets) and it was not always possible to establish their intended purpose with certainty. In the few cases were there could have been uncertainty about usages, or when animals were offered for sale for potentially multiple purposes, we made an educated guess using contextual data to include or excluded these observations to eliminate questionable data. Thus, a live chameleon for sale in a shop selling live tortoises is most likely to be sold as a pet, but a live chameleon for sale at the store of an herbalist is more likely to be used for medicinal purposes. Likewise, tortoise carapaces on display at a medicinal shop suggest use in medicine, whereas the same carapace on display in a tourist shop is likely to be sold for decorative purposes. In the market, we requested the asking prices for the most commonly traded species and converted these to US dollars (US\$) using an exchange rate of nine Dirham (MAD) to the dollar. We used these prices to calculate the value of each species in trade, and summed them to arrive at an overall value of the trade. Asking prices will go down after bartering or when more than one specimen at a time is purchased. Because we did not want to make any purchases, the overall figure we present in our results may overestimate the total value of the trade.

For each species in each market, we calculated the average number of species that we observed per survey (i.e., dividing the total number of individuals observed in a particular town by the number of surveys that were conducted in that town). We used four cities that were surveyed multiple times (i.e., Casablanca, Fez, Marrakesh, and Meknes), which we believe are representative of different aspects of the trade in reptiles in Morocco, to compare markets in more detail. For each market city and for each survey, we calculated the total 
number of species for sale as a measure of species richness, as well as the proportion of trade in live animals versus dried animals; differences between market cities were tested using ANOVAs.

We calculated minimum turnover of Mediterranean chameleon and Bell's Dabb lizard two commonly observed species, by repeat visits to eight individual shops for the chameleons (four shops in Marrakesh, two shops in Fez and Rabat) and six individual shops for Bell's Dabb lizard (four shops in Meknes, two shops in Marrakesh), all within a four-week period. It was not possible to calculate turnover when in between surveys a new consignment of animals had arrived and the number of Mediterranean chameleons or Bell's Dabb lizards in the shops had increased; our turnover figures thus are minimum estimates. Using the fourweek turnover figures, we calculated annual numbers of turnover for each city in which we observed Mediterranean chameleons or Bell's Dabb lizards for sale and combined them for an overall annual figure. For the other species, we were not able to collect firm data on turnover but, given the non-perishable nature of many items, we expect that at least parts of the inventory can remain unsold for several months. To reduce the effect of non-independence of data in exploring temporal patterns, we used data from surveys done at least three months apart.

For testing whether observed frequencies of occurrence were homogeneously distributed over all classes, and whether significant differences existed between the different classes, we used sequential chi-square tests. Expected frequencies were generated based on a random distribution proportional to sampling effort per market or per survey. Pearson product-moment correlation coefficients were calculated to explore correlates with trade volumes. Statistics were run in $R(R$ Development Core Team, 2015); we present means and ranges and accepted significance when $\mathrm{P}<0.05$.

Table 1. Mean number of reptiles traded for medicinal purposes in 20 Moroccan towns in 2013 and 2014. For towns that were surveyed more than once, the range is given. Values in italics include live individuals and values in normal font represent traded in dried specimens only. No snakes were identified to species. Key to genus names: $T .=$ Testudo, $C .=$ Camaeleo, U. $=$ Uromastryx, V. $=$ Varanus, $C$. $=$ Crocodylus,$N .=$ Naja,$B .=$ Bitis, $P .=$ Python . Snakes refers to unidentified snakes other than Egyptian cobra, puff adder or African rock python.

\begin{tabular}{|c|c|c|c|c|c|c|c|c|c|c|}
\hline $\begin{array}{l}\text { City } \\
\text { (number of } \\
\text { surveys) }\end{array}$ & $\begin{array}{l}\text { Spur-thighed } \\
\text { tortoise } \\
\text { (T. gracae) }\end{array}$ & $\begin{array}{l}\text { Mediterranean } \\
\text { chameleon } \\
\text { (C.chamaeleon) }\end{array}$ & $\begin{array}{l}\text { Bell's Dabb } \\
\text { monitor lizard } \\
\text { (U.acanthinura })\end{array}$ & $\begin{array}{l}\text { Desert } \\
\text { lizard } \\
\text { (V.griseus) }\end{array}$ & $\begin{array}{l}\text { Nile } \\
\text { crocodile } \\
\text { (C. niloticus) }\end{array}$ & $\begin{array}{l}\text { Egyptian } \\
\text { cobra } \\
(N \text {. haje })\end{array}$ & $\begin{array}{l}\text { Puff } \\
\text { adder } \\
\text { (B.arietans) }\end{array}$ & $\begin{array}{l}\text { African } \\
\text { rock python } \\
\text { (P. sebae) }\end{array}$ & Snake & Total \\
\hline $\mathrm{Fez}(6)$ & $0.5(0-2)$ & $5.7(0-13)$ & $10.8(4-33)$ & $0.7(0-1)$ & $3.2(2-4)$ & 0 & 0 & $5.3(2-14)$ & 0 & 26.2 \\
\hline Meknes (6) & $0.3(0-2)$ & $9.3(0-55)$ & $12(6-20)$ & $0.7(0-1)$ & 0 & $0.3(0-1)$ & $1.7(0-5)$ & $4.7(3-6)$ & $0.8(0-3)$ & 29.3 \\
\hline Rabat (5) & $0.2(0-1)$ & $10.7(0-32)$ & $0.7(0-3)$ & 0 & $0.5(0-2)$ & 0 & 0 & $2.8(0-4)$ & 0 & 14.8 \\
\hline Marrakesh (5) & $7.2(5-10)$ & $71.2(16-237)$ & $39.6(4-79)$ & $0.4(0-1)$ & $4.4(2-7)$ & $4(0-9)$ & $10.8(0-18)$ & $24.4(6-40)$ & $1.4(0-3)$ & 163.4 \\
\hline Tangier (4) & 0 & $0.75(0-3)$ & $4(0-23)$ & 0 & 0 & 0 & 0 & 0 & 0 & 8.8 \\
\hline Casablanca (3) & $3.3(0-10)$ & $61(23-106)$ & $15.7(8-31)$ & 0 & $1.3(0-3)$ & 0 & 0 & $4.3(0-5)$ & 0 & 85.7 \\
\hline Sale (2) & 0 & $2(0-4)$ & $0.5(0-1)$ & $2.5(2-3)$ & 0 & 0 & 0 & 0 & 0 & 5 \\
\hline Taroudant (2) & 0 & $2.5(0-5)$ & 0 & 0 & 0 & 0 & 0 & $1(0-2)$ & 0 & 3.5 \\
\hline Tetuan (2) & $1.5(0-3)$ & 0 & $1(0-2)$ & 0 & 0 & 0 & 0 & 0 & 0 & 2.5 \\
\hline Agadir (1) & 0 & 3 & 0 & 0 & 0 & 0 & 0 & 1 & 0 & 4 \\
\hline Asilah (1) & 0 & 0 & 0 & 0 & 0 & 0 & 0 & 0 & 0 & 0 \\
\hline Beni Nsar (1) & 0 & 0 & 0 & 0 & 0 & 0 & 0 & 0 & 0 & 0 \\
\hline Chefchaouen (1) & 1 & 0 & 0 & 0 & 0 & 0 & 0 & 0 & 0 & 1 \\
\hline El Jadida (1) & 0 & 0 & 0 & 0 & 0 & 0 & 0 & 0 & 0 & 0 \\
\hline Essaouira (1) & 0 & 0 & 0 & 0 & 0 & 0 & 0 & 0 & 0 & 0 \\
\hline Fnideq (1) & 0 & 0 & 0 & 0 & 0 & 0 & 0 & 0 & 0 & 0 \\
\hline Kenitra (1) & 0 & 0 & 2 & 0 & 0 & 0 & 0 & 0 & 0 & 2 \\
\hline Ouijda (1) & 2 & 11 & 4 & 0 & 0 & 0 & 0 & 0 & 0 & 17 \\
\hline Safi (1) & 0 & 0 & 0 & 0 & 0 & 0 & 0 & 0 & 0 & 0 \\
\hline Taza (1) & 0 & 0 & 0 & 0 & 0 & 0 & 0 & 1 & 0 & 1 \\
\hline Total (\% markets) & $57(40 \%)$ & $720(45 \%)$ & $428(50 \%)$ & $15(20 \%)$ & $52(20 \%)$ & $22(10 \%)$ & $61(10 \%)$ & $219(40 \%)$ & $12(10 \%)$ & $1.586(70 \%)$ \\
\hline
\end{tabular}




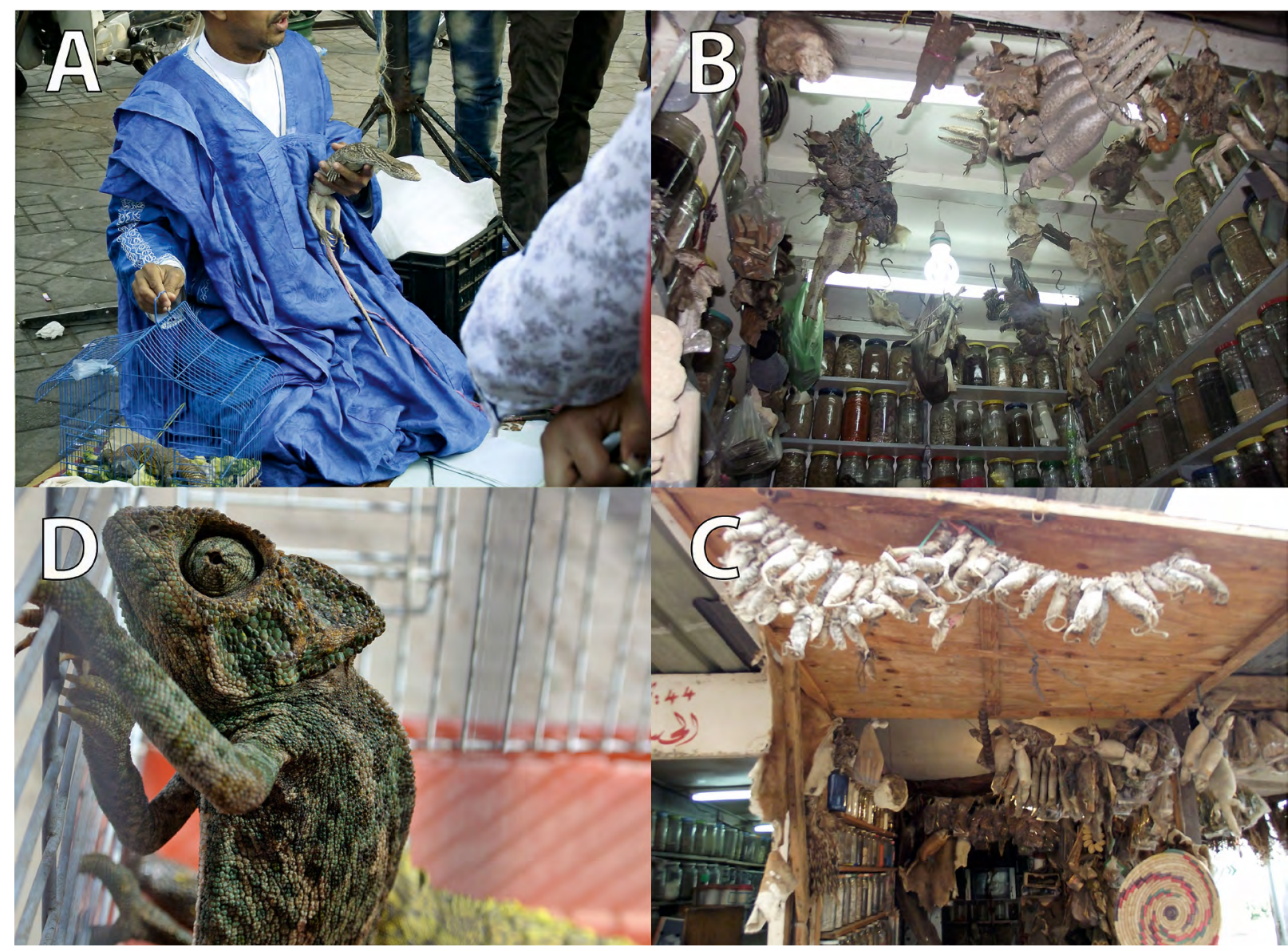

Fig. 2. Trade of reptiles for medicinal purposes in Morocco, clockwise from top left: (A) vendor with desert monitor lizard and Bell's Dabb lizards at herbalist stall in Meknes advertises medicinal products; (B) herbalist stall in Marrakesh; (C) herbalist stall in Casablanca both selling dried Mediterranean chameleons and stuffed Bell's Dabb lizards; and (D) live Mediterranean chameleon and Bell's Dabb lizard at a herbalist in Fez. All photographs by Daniel Bergin.

\section{Results}

\section{Volume and value of the trade}

We observed that herbalists displayed protected wildlife openly on the street or in the front of their shops and did not appear concerned about regulations banning sale of the species they displayed; this allowed us to accurately assess the levels of trade. We recorded at least nine species of reptile in trade for medicinal purposes (Fig. 2). The most common was the Mediterranean chameleon, followed by Bell's Dabb lizard, African rock python, spur-thighed tortoises, and desert monitor lizards (Varanus griseus; Table 1). These species were not equally abundant in the markets $\left(\chi^{2}=\right.$ $657.1, \mathrm{df}=5, P<0.001)$. The desert monitor lizard, Nile crocodile, Egyptian cobra (Naja haje Linnaeus, 1758), and puff adder (Bitis arietans Merrem, 1820) were each observed in smaller numbers than expected when compared to the other remaining species combined (all $\chi^{2}>28.9$, df $=1, P<0.001$ ), whereas the spurthighed tortoise, Bell's Dabb lizard, and Mediterranean chameleon were all observed in higher numbers than expected $\left(\chi^{2}>23.4\right.$, df $\left.=1, P<0.001\right)$. Only the African rock python was observed in numbers that did not differ from the expected values when compared to all other species combined $\left(\chi^{2}=0.20, \mathrm{df}=1, P>0.60\right)$.

The volumes of the four most common species in trade in the six cities with the largest volumes of these species show that the species are not traded in equal proportions in these cities $\left(\chi^{2}=38.0, \mathrm{df}=15, P=0.02\right)$. Thus, Mediterranean chameleon and African rock python were observed in smaller numbers in Casablanca than can be expected on the basis of the number of 
these species in other markets relative to the number of other species observed in Casablanca $\left(\chi^{2}=67.5, \mathrm{df}=1\right.$, $P<0.001$ for the Mediterranean chameleon, and $\chi^{2}=$ 267.6, df $=1, P<0.001$ for the African rock python). Conversely, the number of Bell's Dabb lizard in Meknes was higher than expected on the basis of the overall (across cities) proportion of this species $\left(\chi^{2}=105.1\right.$, $\mathrm{df}=1, P<0.001)$.

Prices for the Moroccan species were generally low, with asking prices for spur-thighed tortoise carapace being around US\$11, Mediterranean chameleons US\$6-44, Bell's Dabb lizards US\$13-22, and desert monitor lizards around US\$55. Skins of Nile crocodiles and African rock pythons were considerably higher, with the former demanding prices of US\$388665 and the latter US\$133-665. While more expensive species were less common in trade, there was no significant relationship between the mean value and the volumes observed in trade $(\mathrm{r}=-0.26, \mathrm{n}=6, P=0.61)$. The combined the retail value of all the items observed during the 49 surveys was about US\$100,000 (MAD900,000 ), with some $70 \%$ of this value made up of species not, or no longer, native to Morocco. The mean turnover for Mediterranean chameleons after four weeks in the eight shops monitored was $66 \%$ (range $40-100 \%$ ), resulting in an annual turnover of 1,520 chameleons (range 921-2,303). The mean turnover for Bell's Dabb lizards after four weeks in the six shops monitored was $66 \%$ (range 31-100\%), resulting in an annual turnover of 775 lizards (range 364-1,174).

\section{Comparing markets}

Reptiles were traded for medicinal purposes in 14 of the 20 markets we surveyed in Morocco and the trade in these markets differed in several ways (Table 1). No medicinal reptile trade was observed in the Spanish exclaves of Ceuta and Melilla. In eight markets, we observed small numbers (fewer than nine individuals) of reptiles, often comprising one or two species; in four markets, we found intermediate numbers (14-30 individuals) of three to eight species and in two markets, large numbers ( $>85$ individuals) of five to nine species. There was a positive association between the size of the city (in terms of human inhabitants) and the number of reptiles for sale (Pearson's $r=0.76, \mathrm{n}=22$, $P<0.001$; Fig. 3); this association remained significant after the exclusion of cities where no reptiles were observed $(\mathrm{r}=0.69, \mathrm{n}=14, P=0.006)$. In Casablanca and Marrakesh, the most commonly observed reptiles we observed in trade were Mediterranean chameleons,

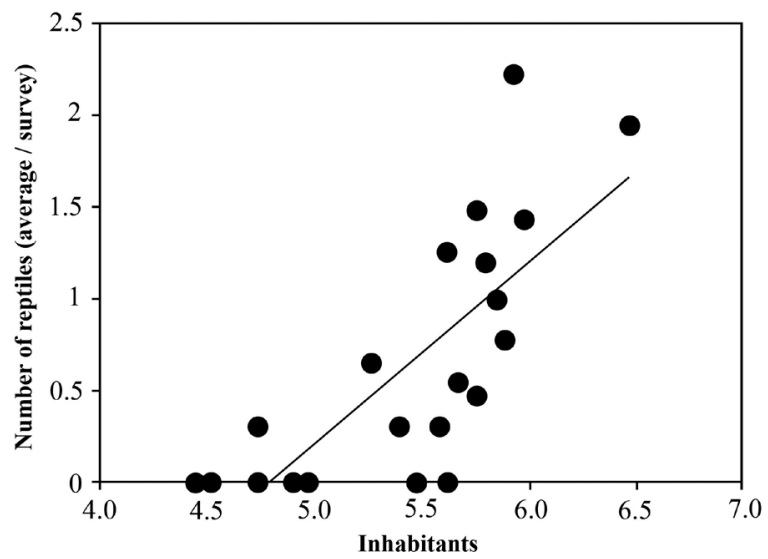

Fig. 3. Relationship between the average number of reptiles offered for sale per survey in 22 cities surveyed in Morocco and the number of human inhabitants in these cities. Data are log-transformed; the maximum average number of reptiles was 163.4 (in Marrakesh) and the largest city is Casablanca with 2.9 million inhabitants.

whereas Bell's Dabb lizards were equally or more common in Fez and Mekness. For cities where reptiles were offered for sale, there was a positive association between the size of a city and the number of herbalists $(\mathrm{r}=0.54, \mathrm{n}=14, P=0.05)$, and there was a very strong positive association between the number of herbalists and the total number of reptiles for sale $(\mathrm{r}=0.82, \mathrm{n}=$ $14, P<0.001)$.

Based on our qualitative observations, the market in Casablanca clearly was oriented towards the local population, being geographically distinct from the tourist section, and only Moroccans were observed in this area. Reptiles were mostly sold in wooden shops located in a dedicated medicinal area. In Fez, the shops with reptiles for sale were in and around the general tourist area and slightly off to the side streets. The shops in Fez were more solidly built and were more frequented by tourists than in Casablanca. Marrakesh was much more geared towards tourists and the three sections where herbalists sold traditional medicine were all located in the main market. Reptiles were sold in shops, stalls, and in ground stalls. In Meknes, ground stalls were particularly common and trade was clearly geared towards the local customers. Bottles with pictures of animals were common in the ground stalls in Meknes and Marrakesh. The vendors of these ground stalls would, in the evenings, hold up live reptiles and call out to passers-by, advertising their me- 


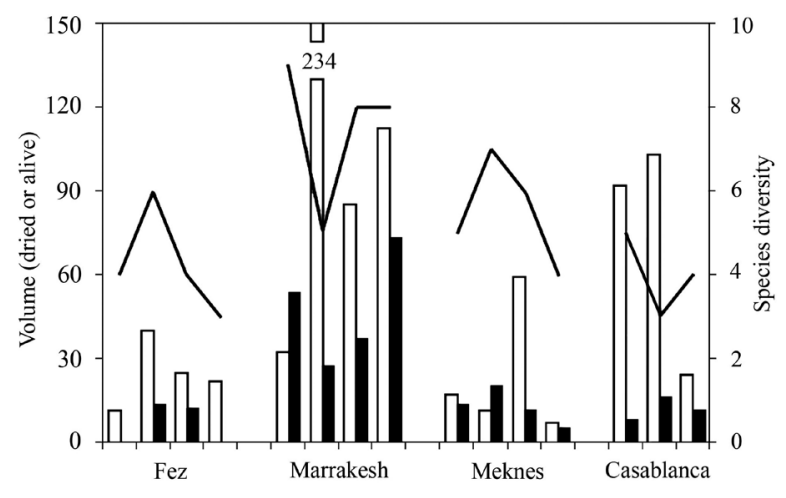

Fig. 4. Trade in reptiles for medicinal purposes in four Moroccan markets surveyed between April 2013 and December 2014. Open bars are dried specimens and solid bars are live individuals (the number of dried specimens in Marrakesh in June 2013 was 234 and is outside the scale); lines represent species diversity.

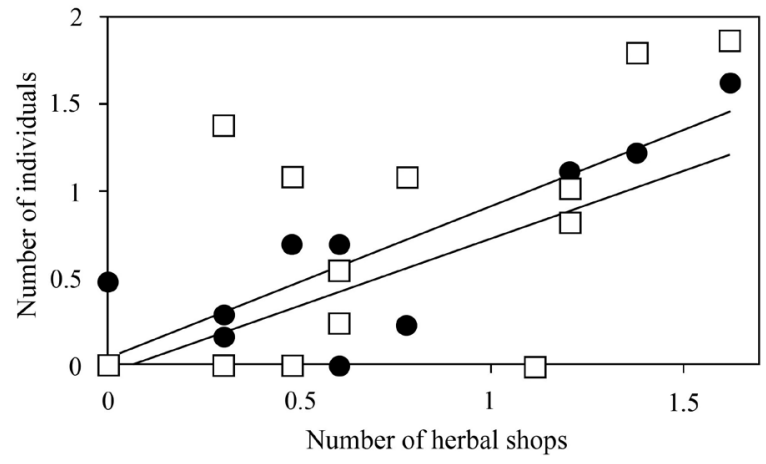

Fig. 5. Relationship between the number of herbal shops in a city and the mean number of Mediterranean chameleons (open squares, upper regression line) and Bell's Dabb lizards (filled circles, lower regression line) for sale in 14 cities where reptiles are sold for medicinal purposes. Data are log-transformed. The maximum number of herbal shops was 41, the maximum number of Mediterranean chameleon was 71.2 individuals, and the maximum number of Bell's Dabb lizard was 39.6 individuals, all in Marrakesh.

and Casablanca, both with up to 10 carapaces per survey, but generally numbers of carapaces were low.

The most commonly traded reptile was the Mediterranean chameleon, which was offered for sale in half of the markets surveyed. We recorded 720 individuals, 214 of them alive and 506 dried and stuffed. Numbers were highest in Marrakesh (74 alive, 282 dried, recorded in each survey with up to 237 per survey) and Casablanca (24 alive, 159 dried, recorded in each survey with up to 106 per survey), but the species is also frequently traded in Rabat (61 alive, none dried, recorded in all but one survey with up to 32 per survey). We recorded chameleons only once out of six surveys when we found 55 dried specimens in Meknes in April 2014. There was a clear relationship between the number of herbal shops in a city and the number of chameleons that were offered for sale $(\mathrm{r}=0.58, \mathrm{n}=14$, $P=0.03$; Fig. 4).

Bell's Dabb lizards were traded in significant quantities in 10 cities: 428 individuals (181 live, 247 dried or stuffed), with highest numbers in Marrakesh (98 live, 100 dried) and Meknes (42 live, 30 dried). Just as with chameleons, there was a clear relationship between the number of herbal shops in a city and the number of Bell's Dabb lizards that are offered for sale ( $\mathrm{r}=0.66, \mathrm{n}=14, P=0.01$; Fig. 5). We were informed that burning them was helpful for your eyes and that keeping one in a new house brought good luck. 
We recorded small numbers of desert monitor lizards, with one live individual in Meknes, two live individuals in Marrakesh, five stuffed in Sale, and four stuffed in Fez. One vendor had a bottle with liquid in which he claimed there were monitor lizard parts, advertised as Sahara Medicine, but we were unable to verify whether or not the species was indeed bottled. Desert monitor lizard parts were said to increase virility.

We observed Egyptian cobras, puff adders and other unidentified snakes in Marrakesh (81 live specimens) and in Meknes (14 specimens) only. We were not able to determine how the snakes were used when alive, although they may have been displayed to draw in the crowds. We saw African rock python skins in eight of the 20 cities. The largest numbers we observed were in Marrakesh (122), Fez (32), and Rabat (17). We observed 52 Nile crocodiles, either as skins (27) or as stuffed specimens (25) and we observed the highest numbers in Fez (18) and Marrakesh (22). African rock python skins have been used as relief for asthma, but it is unclear what medical uses skins or the stuffed crocodiles have.

\section{International trade in pythons and crocodiles into Morocco}

African rock pythons and Nile crocodiles are not (or no longer) native to Morocco, and must have been imported from countries to the south or southeast of Morocco. Morocco has never reported any imports of African rock pythons to the CITES Secretariat (i.e., there are no recorded imports in the CITES trade database), but several West African countries reported the export of African rock python to Morocco between 1986 and 2007 (Guinea, one live individual in 1986; Sudan, six skins in 1991; Chad, three skins in 2000, and Niger, 62 live individuals in 2002 and 806 skins in 2000-2007). If the skins observed in the markets in 2013-2014 were indeed part of these imports, then some of them must have been imported in 2007 the latest. Morocco reported the import of four live Nile crocodile for a zoo in 1999 to the CITES Secretariat, but several countries reported the export of Nile crocodile to Morocco between 1991 and 2007. If the skins and stuffed crocodiles observed in the markets in 2013-2014 were indeed part of these imports, then some of them must have been imported in 2007 at the latest.

\section{Discussion}

\section{Generalities of the trade and its uses}

We show a sustained availability and significant trade in reptiles throughout Morocco to meet the demand for traditional medicine. We observed Mediterranean chameleon, Bell's Dabb lizard, and spur-thighed tortoises in the hundreds. Our turnover data suggest that the demand for traditional medicine is responsible for the extraction of possibly more than a thousand Mediterranean chameleons and Bell's Dabb lizards every year. We think that the way we measured turnover is conservative (i.e., checking a small number of shops over four-week periods is probably not enough to capture the intricacies of a dynamic market) and that real numbers of reptiles sold for medicinal purposes on an annual basis may be considerably more. While the turnover data we collected gave us some insight in the dynamics of the reptile-for-medicine trade, it is clear that a more comprehensive understanding of the dynamics, both temporal and spatial, that govern the use of reptiles as sources for medicine is of paramount importance. This is all the more true given that such uses are seldom exclusively based on animals and usually also includes plants (Alves et al., 2013).

Our observations in the contemporary markets in Morocco suggest very similar uses of some of the more commonly traded reptiles compared to that what has been reported in the past. At the same time some very specific uses are mentioned by earlier visitors to the country that were not recorded by us. Thus, Westermark (1926) noted that tortoise carapaces when burned and the smoke inhaled could cure a person who had become a victim of witchcraft. Tortoise carapaces, again when burned, can also be used by a married woman for taming her rowdy and quarrelsome husband (Westermark, 1926). Tortoise carapace may also be used for trembling hands, insomnia, and anxiety (Akhmisse, 1985). Westermark (1926) noted that contact with the blood or urine of a tortoise can cause warts (which in turn can be cured by applying the blood of a hedgehog), but, according to Highfield and Bayley (2007), its blood is a sure cure for warts.

Now and in the past, Mediterranean chameleons have a wide range of uses and are used to cure a variety of illnesses, including, according to many older sources, ones that are linked to witchcraft and warding off the evil eye (Jackson, 1810; Leared, 1876; Westermarck, 1926; Fogg, 1938, 1941; Akhmisse, 1985). Dried chameleon cooked in butter and eaten in small 
quantities, or when burned and the smoke inhaled, is considered a remedy against sickness, nausea, and debility. We were informed that burning chameleons would guard against bad luck and combat curses wished upon one by another person. A tonic infused with a chameleon can be used as a cure for fever. When charred and pounded, a chameleon is a remedy for skin abscess, and applied externally it is a cure for insect stings or bites. Meziane (2003) noted that the flesh of a chameleon was used to prevent or to remedy female sterility, frigidity, and impotence in northern Morocco. Jackson (1810) noted that a chameleon split open alive was a common application to wounds and sores; we do not know whether this practice (splitting chameleons open alive) is still in vogue, but we did not observe it nor was it pointed out to us.

We were informed that Bell's Dabb lizard, when burned, was helpful for your eyes and that keeping one in a new house brought good luck. Fogg (1941) reported that inhaling the smoke of a pounded and burned lizard is a remedy for a scorpion or snakebite as well as for sickness believed due to poisoning through having eaten bewitched food. In the south of Morocco, infants' feeding bottles are traditionally made from dried Bell's Dabb lizards (Highfield and Bayley, 2007). The only other country where Bell's Dabb lizards (and indeed other Uromastyx lizards) are traded for medicinal purposes in a contemporary society appears to be Malaysia where there is an ongoing trade in especially their oil (Knapp, 2004; Ching and Chng, 2016). In Malaysia the products of Uromastyx lizards appear to target a Muslim audience as products are promoted as halal, a binding Islamic certification concerning the consumption of certain products or foods according to religious rules (Ching and Chng, 2016).

We recorded a limited number of uses for snakes and lizards other than Bell's Dabb lizard. The Tuaregs believe that the head of a desert monitor lizard is a potent talisman against snakebites (Highfield and Bayley, 2007). According to Fogg (1941) snake skin has several uses. Inhaling the smoke of a pounded and burned snake, is a remedy for fever, for heart trouble, or for any kind of serious disease or affliction, and rubbed on the eyes of a person it is a remedy for watery eyes, or a preventive of such. Snake-fat is remedy for hemorrhoids.

Our survey suggests that in contemporary Morocco, there is still a need and a desire to use animalbased traditional medicine. Reptiles and/or their parts are believed to cure a range of ailments including sick- ness, nausea, fever, external wounds or bites, and, less frequently, anxiety, insomnia or fertility-related illnesses, in particular when the cause of these ailments is linked to witchcraft and warding off the evil eye. Most of the species we observed in trade were known to be used in Morocco for medicinal purposes (Jackson, 1810; Leared, 1876; Highfield and Bayley, 2007), and indeed as such have been included in a recent compendium of reptiles used in traditional folk medicine (Alves et al., 2008; 2013). Given that no non-African reptiles were observed during any of our surveys, we believe that the stuffed iguanas (an exclusively New World taxon) reported by Martin and Perry-Martin (2012) most likely refers to misidentified Bell's Dabb lizards (or even North African eyed lizard, noting that we did not observe this species in trade). Besides their supposed role in healing, it is clear that the reptiles often have magical-religious significance, reflecting the different views of health and disease that exist amongst cultures; animal parts are used to prepare clinical remedies as well as to make amulets or charms used in magical diagnoses (Alves et al., 2008).

The popularity of reptile-based medicine, as well as its perceived efficiency, is influenced by cultural aspects, traditions, and social economic relations. Traditional folk medicine is widely available and affordable, and generally accessible to most people. While it is tempting to think that in contemporary societies it is to be largely confined to remote rural areas, our study shows that availability in cities (most if not all of them having one or several hospitals practicing evidencebased medicine) remains high.

It is clear that the trade in reptiles, protected or not, is poorly regulated in Morocco's markets (Benardouze et al., 2004; Bergin and Nijman, 2014; Nijman et al., 2016). Either traders are unaware of the rules and regulations that preclude trade in protected species or they believe that the authorities allow them to continue to offer these species for sale without repercussions. While market data appear to have limited value in gauging off-take levels from populations in the wild, population data of many Moroccan reptiles are not robust enough to assure that collection of reptiles for the medicine trade does not have a detrimental effect. Unfortunately, Morocco's track record with respect to environmental and species protection is far from reassuring. Morocco ranks relatively low on the Biodiversity and Habitat protection component of the global Environmental Performance Ranking as it ranks 134 out of 177 countries that were assessed in 2014 (Hsu et $a l .$, 2014). Compared to its neighbours, Morocco is 
ranked just above Tunisia (136), but below Mauretania (132), Algeria (130), Spain (101) and Portugal (83).

While we found a great number of similarities in the nature of the reptile trade between cities throughout Morocco, there are also some clear differences. In Fez and Casablanca, small numbers of species were on offer and these were mostly in the form of dried specimens, whereas in Marrakesh and Meknes a large variety of species was available and these included a larger number of live animals. What was common in these four markets, and indeed the other cities where we observed the reptile trade, is the openness of the trade.

\section{Legality and regulation of trade}

The spur-thighed tortoise and the three species of lizard we observed in trade are included on the list of protected species, precluding all trade in them, and all four plus the two identified species of snake are considered threatened at the national level (Franchimont and Saadaoui, 2001). Morocco is one of four African countries that have acceded to the Convention on the Conservation of European Wildlife and Natural Habitats (Bern Convention). The Convention regulates species conservation by imposing restrictions on taking species from the wild and on exploitation. It furthermore constitutes a commitment to protect the habitat of species. The spur-thighed tortoise and the Mediterranean chameleon are included on Appendix II: Strictly Protected Fauna Species, and these may not be disturbed, captured, killed, or traded. Bell's Dabb lizard and desert monitor lizard are included on Appendix III: Protected Fauna Species, and these species may only be hunted or otherwise exploited in exceptional instances.

In January 2011, Law No. 29-05 on the Protection of Species of Wild Flora and Fauna and their Trade was promulgated and adopted at national level (Bergin and Nijman, 2016), and can now be implemented. Included with this law is a list of protected species for which the importation, capture, sale, offer for sale, or killing is illegal without a specific license. Lawbreakers can be fined up to US $\$ 11,000$ for illegal trade in selected species. Falsifying or misusing permits can lead to fines of up to US $\$ 5,500$. However, our interpretation of the current law is that government inspectors are not allowed to enter shops to check for the presence of protected wildlife or wildlife products without permission from the owners (Martin and Perry-Martin, 2012). Martin and Perry-Martin (2012) further noted that current laws do permit government authori- ties to inspect and confiscate illegal wildlife cargo at the international land borders, airports and seaports, thus confirming the existence of an Airport Bias with the authorities failing to detect the majority of illicit trade (Phelps et al., 2010).

Morocco ratified the Convention on International Trade in Endangered Species of Wild Fauna and Flora (CITES) in 1976. Unfortunately, hitherto the implementing legislation does not meet all of the requirements of the Convention. Once Law No. 29-05 is signed and properly implemented, it is expected that Morocco's legislation will meet the requirements. Almost all reptile species observed in trade are included on CITES Appendix II. A species is included on this appendix if there is a high likelihood that if trade is not closely controlled it may become threatened with extinction. Following the Convention, international trade in specimens of Appendix-II species may be authorized by the granting of an export permit or re-export certificate. Permits or certificates should only be granted if the relevant authorities (in Morocco Le Haut Commissaire aux Eaux et Forêts et à la Lutte Contre la Désertification, known as Eaux et Forêts) are satisfied that certain conditions are met, above all that trade will not be detrimental to the survival of the species in the wild. It is encouraging that we did not observe any reptiles for medicinal purposes for sale in the Spanish cities of Ceuta or Melilla nor in the Moroccan cities of Fnideq or Beni Nsar, bordering Ceuta and Melilla, suggesting that the flow of wildlife from Morocco to Europe via this route is either not open or at least is small.

Morocco is not unique in its struggle against the illegal wildlife trade, and reptiles are traded the world over with and without permits. In a recent review, drawing on examples from the global trade in reptiles for the pet market, Auliya et al. (2016) concluded that "There are limited resources in many regions that result in under-staffed national authorities. This in turn provides the conditions necessary to circumvent national and international regulations. Better implementation of current regulations, including a checks and balances approach as well as strengthening of enforcement is necessary" thus clearly echoing our experiences in Morocco. In the foreseeable future it can be expected that reptiles will continue to be traded in many of the market towns included in our survey. In light of recent developments in terms of improved legislation and given the commitment Morocco has expressed through international treaties (CITES, Bern Convention) there is some hope for optimism with 
respect to curbing the illegal trade in protected and globally threatened reptiles. However, these regulations will not be effective without increased enforcement and, crucially, enforcement actions that extend to all levels of the judiciary from local police officers to judges in the highest courts.

\section{Acknowledgements}

We thank the students of P10203 International Legislation, Humans and Wildlife at Oxford Brookes University for helpful discussions and feedback, Els van Lavieren (Moroccan Primate Conservation, Amsterdam), Isabelle Six, and Mohamed Amezian (Groupe de Recherche pour la Protection des Oiseaux au Maroc, Rabat) for information and support, and Ann Paterson (Williams Baptist College, Walnut Ridge) for reviewing earlier versions of this paper. Juan M Pleguezuelos and two anonymous reviewers provided helpful suggestions for improvement.

\section{References}

Adeola MO. 1992. Importance of wild animals and their parts in the culture, religious festivals, and traditional medicine, of Nigeria. Environmental Conservation 19: 125-134.

Akhmisse M. 1985. Médecine, Magie, et Sorcellerie au Maroc: ou, L'art Traditionnel de Giérir. Benimed, Casablanca, Morocco.

Alves RR, da Silva Vieira WL, Santana GG. 2008. Reptiles used in traditional folk medicine: conservation implications. Biodiversity and Conservation 17: 2037-2049.

Alves RR, Leo Neto NA, Santana GG, Vieira WL, Almeida WO. 2009. Reptiles used for medicinal and magic religious purposes in Brazil. Applied Herpetology 6: 257-274.

Alves RR, Vieira WLS, Santana GG, Vieira KS, Montenegro PFGP. 2013. Herpetofauna used in traditional folk medicine: conservation implications. Pp. 109-133 in: Alves RR, Rosa IL, eds, Animals in traditional folk medicine. Heidelberg, Germany: Springer.

Auliya M, Altherr S, Ariano-Sanchez D, Baard EH, Brown C, Brown RM, Cantu JC, Gentile G, Gildenhuys P, Henningheim E, Hintzmann J, Kanari K, Krvavac M, Lettink M, Lippert J, Luiselli L, Nilson G, Nguyen TO, Nijman V, Parham JF, Pasachnik SA, Pedrono M, Rauhaus A, Rueda Córdova D, Sanchez ME, Schepp U, van Schingen M, Schneeweiss N, Segniagbeto GH, Somaweera R, Sy EY, Türkozan O, Vinke S, Vinke T, Vyas R, Williamson S, Ziegler T. 2016. Trade in live reptiles, its impact on wild populations, and the role of the European market. Biological Conservation 204: 103-119.

Benhardouze W, Tiwari M, Aksissou M, Viseux B, Godfrey MH. 2004. Notes from preliminary market surveys in Morocco. Marine Turtle Newsletter 104: 8-9.

Bergin D, Nijman V. 2014. Open, unregulated trade in wildlife in Morocco's markets. TRAFFIC Bulletin 26: 65-70.

Bergin D, Nijman V. 2016. Potential benefits of impending Moroccan wildlife trade laws, a case study in carnivore skins. Biodiversity and Conservation 25: 199-201.
Byard RW. 2016. Traditional medicines and species extinction: another side to forensic wildlife investigation. Forensic Science, Medicine, and Pathology 12: 125-127.

Caillabet OS. 2013. The trade in tokay geckos Gekko gecko in South-East Asia: with a case study on novel medicinal claims in Peninsular Malaysia. Petaling, Jaya: TRAFFIC.

Ching OO, Chng SCL. 2016. The use of spiny-tailed lizards Uromastyx spp. for medicinal purposes in Peninsular Malaysia. TRAFFIC Bulletin 28: 35-40.

Cox N, Chanson J, Stuart S. 2006. The status and distribution of reptiles and amphibians of the Mediterranean Basin. International Union for the Conservation of Nature Cambridge, UK.

Fogg W. 1938. A tribal market in the Spanish zone of Morocco. Journal of the International African Institute 11: 428-58.

Fogg W. 1941. The wares of a Moroccan folk-doctor. Folklore 52: 273-303.

Franchimont J, Saadaoui EM. 2001. Etude Nationale sur la Biodiversite - Rapport de Synthese. $2^{\text {nd }}$ Edition. Observatoire National de L'Environnement du Maroc, Rabat, Morocco.

Gong SP, Chow AT, Fong JJ, Shi HT. 2009. The chelonian trade in the largest pet market in China: scale, scope and impact on turtle conservation. Oryx 43: 213-216.

Harris DJ, Vasconcelos R, Brito JC. 2007. Genetic variation within African spiny-tailed lizards (Agamidae: Uromastyx) estimated using mitochondrial DNA sequences. AmphibiaReptilia 28: 1-6.

Hsu A, Emerson J, Levy M, de Sherbinin A, Johnson L, Malik O, Schwartz J, Jaiteh M. 2014. The 2014 Environmental Performance Index. Yale Center for Environmental Law and Policy, New Haven, Connecticut, USA.

Humle T, Konate A. 2015. Primates and bushmeat hunting around the High Niger National Park, Guinea, West Africa: drivers and patterns of change. Folia Primatologica 86 : 298.

Jackson JG 1810. An account of the empire of Morocco, and the district of Suse. Philadelphia, Pennsylvania, USA: Francis Nichols, Fry and Kammerer.

Knapp A. 2004. An assessment of the international trade in spiny-tailed lizards Uromastyx with a focus on the role of the European Union. CITES Doc AC Inf. 13, CITES, Geneva.

Leared A. 1876. Morocco and the Moors: being an account of travels, with a general description of the country and its people. London, UK: Gilbert and Rivington.

Martin E, Perry-Martin C. 2012. Tourists underwrite Morocco's illegal trade in wildlife artifacts. Swara (Jul-Sep): 16-29.

Magnino S, Colin P, Dei-Cas E, Madsen M, McLauchlin J, Nöckler K, Maradona MP, Tsigarida H, Vanopdenbosch E, Van Peteghem C. 2009. Biological risks associated with consumption of reptile products. International Journal of Food and Microbiology 134: 163-175.

Mahawar MM, Jaroli DP. 2008. Traditional zootherapeutic studies in India: a review. Journal of Ethnobiology and Ethnomedicine 4: 17.

Martínez-Freiría F, Argaz H, Fahd S, Brito JC. 2013. Climate change is predicted to negatively influence Moroccan endemic reptile richness. Implications for conservation in protected areas. Naturwissenschaften 100: 877-889.

Meziane M. 2003. Origines de la medicine traditionnelle morocaine: Enquette de terrain dans la region D'Oujda. Ph.D. dissertation. University of Nantes, Nantes, France. 
Newman DJ, Cragg GM. 2012. Natural products as sources of new drugs over the 30 years from 1981 to 2010. Journal of Natural Products 75: 311-335.

Nijman V, Nekaris KAI, Bickford DP. 2012a. Small species at risk from Asian medicine. Nature 481: 265.

Nijman V, Shepherd CR, Mumpuni, Saunders KL. 2012b. Overexploitation and illegal trade of reptiles in Indonesia. Herpetological Journal 22: 83-89.

Nijman V, Bergin D, van Lavieren E. 2016. Conservation in an ever-globalizing world: wildlife trade in, from, and through Morocco, a gateway to Europe. Pp 313-323 in: Aguirre AA, Sukumar R, eds, Tropical conservation: perspectives on local and global priorities. Oxford University Press, Oxford, UK.

Phelps J, Webb EL, Bickford D, Nijman V, Sodhi NS. 2010. Boosting CITES. Science 330: 1752-1753.

Pleguezuelos JM, Brito JC, Fahd S, Feriche M, Mateo JA, Moreno-Rueda G, Reques R, Santos X. 2010. Setting conservation priorities for the Moroccan herpetofauna: the utility of regional red lists. Oryx 44: 501-508.

R Core Team. 2015. R: A language and environment for statistical computing. R Foundation for Statistical Computing, Vienna, Austria. Available at http: //www.R-project.org/. [accessed 15 January 2016]

Rowley JJ, Shepherd CR, Stuart BL, Nguyen TQ, Hoang HD, Cutajar TP, Wogan GO, Phimmachak S. 2016. Estimating the global trade in Southeast Asian newts. Biological Conservation 199: 96-100.

Sadovy Y, Cheung WL. 2003. Near extinction of a highly fecund fish: the one that nearly got away. Fish and Fisheries 4: 86-99.
Segniagbeto GH, Petrozzi F, Aidam A, Luiselli L. 2013. Reptiles traded in the fetish market of Lomé, Togo (West Africa). Herpetological Conservation and Biology 8: 400-408.

Still J. 2003. Use of animal products in traditional Chinese medicine: environmental impact and health hazards. Complement Therapies Medicine 11: 118-122.

van Lavieren E, Wich SA. 2010. Decline of the endangered Barbary macaque Macaca sylvanus in the cedar forest of the Middle Atlas Mountains, Morocco. Oryx 44: 133-138.

Westermarck E. 1926. Ritual and Belief in Morocco. London, UK: Macmillan.

Whiting MJ, Williams VL, Hibbitts TJ. 2013. Animals traded for traditional medicine at the Faraday market in South Africa: species diversity and conservation implications. Pp. 421-473 in: Alves RR, Rosa IL, eds, Animals in traditional folk medicine. Heidelberg, Germany: Springer.

Znari M, Germano DJ, Mace JC. 2005. Growth and population structure of the Moorish tortoise (Testudo graeca graeca) in westcentral Morocco: possible effects of over-collecting for the tourist trade. Journal of Arid Environments 62: 55-74.

Zhou Z, Jiang Z. 2004. International trade status and crisis for snake species in China. Conservation Biology 18: 13861394.

Received: 30 May 2016

Revised and accepted: 16 September 2016

Published online: 23 February 2017

Editor: S.E.T. van der Meij 